\title{
Editorial
}

\section{Treating adolescents with depression and anxiety disorders, also looking at global functioning and general improvement}

Depression in children and adolescents is a prevalent disorder affecting around $0.25 \%$ of children and $2-3 \%$ of adolescents. In child psychiatric clinics we see many boys before puberty and an increasing number of young females after puberty. Depression usually leads to a considerable degree of suffering and impaired functioning and to an increased risk of suicidal behaviour and suicides (1). In up to twothirds of the cases depression is seen comorbidly with other child and adolescent psychiatric disorders such as anxiety disorders, obsessive-compulsive disorder (OCD), attention-deficit/hyperactivity disorder (ADHD) and eating disorders which are all important for the prognosis of the adolescent patient and have large implications on treatment planning. Depression in adolescents is episodic as in most adult patients. Remission is seen in about $10 \%$ during the first 3 months (untreated) and in 50\% during 12 months. One-third appears not to be remitted after 24 months. The risk of relapse is considerable as 30-40\% appears to relapse during a period of 5 years. In some children and adolescents the disorder turns into bipolar disorder $(2,3)$. It therefore seems very important to aim at early intervention using evidencebased methods in an attempt to improve the shortand long-term outcomes. The evidence of cognitive behavioural therapy alone is strong and there is also evidence that serotonin specific reuptake inhibitors (SSRIs) are efficient (although there seem to be small effect sizes). There have been large randomised, double-blind studies of SSRI-treatment conducted in adolescents with depression showing that there is a statistically significant larger effect of active medicine to placebo. The number needed to treat (NNT) including studies with mild to moderate and severe depression are around ten, described as a response rate of about $60 \%$ for medication and $35-55 \%$ for placebo (4). The efficacy of the medication seems to increase with increasing age in the population of children and adolescents $(5,6)$.
Anxiety disorders such as generalised anxiety, separation anxiety disorder and panic disorders are often seen in childhood and adolescence. Prevalence studies range from $2-3 \%$ to more than $10 \%$ of adolescents suffering from impairing anxiety disorders. Anxiety is a normal phenomenon during all developmental phases, so diagnostics must always take into account the maturity and the age of the child (i.e. what is acceptable for a 5-year-old in terms of being anxious for separation is not acceptable for a 14year-old adolescent). Anxiety disorders in adults very often have their onset in childhood and often lead to a disabling course. Cognitive behavioural therapy (CBT) has proven effective for most anxiety disorders and SSRIs have shown effectiveness especially in the treatment of OCD and also for separation anxiety and generalised anxiety disorder (7). So, early intervention and studies in evidence-based treatment approaches are very important for the population of children and adolescents with anxiety disorders.

Guidelines point to the importance of CBT either alone or in combination with SSRI-treatment in depression and anxiety disorders in adolescence. In this issue of the journal Calati et al. present one of the few meta-analyses on the use of CBT and medication as a combined approach in depression as well as in anxiety disorders in adolescence (8). The scope of their analysis was primarily to analyse global functioning in patients treated with combined treatments. The aspect of global functioning is very important. Too many studies in children and adolescents have been focusing too narrowly on symptom reduction without assessing global functioning and general improvement. Calati et al. conclude that combined treatment seems to be more effective than antidepressant treatment alone on global functioning and general improvement in adolescents with either major depressive or anxiety disorders.

Further research in the area is warranted. Research should focus upon what works for whom, i.e. who 


\section{Editorial}

amongst the depressed or anxious adolescents will benefit sufficiently from CBT? Who will need medication in addition to psychotherapeutic treatment? Thus, hopefully leading to evidence-based stepped care treatment for depression and anxiety disorders in children and adolescents.

\section{Professor, Dr. Per Hove Thomsen Aarhus University Hospital, Regional Centre for Child and Adolescent Psychiatry, Risskov, Denmark}

\section{References}

1. Ford T, Goodman R, Meltzer H. The British Child and Adolescent Mental Health Survey 1999: the prevalence of DSM-IV disorders. J Am Acad Child Adolesc Psychiat 2003;42(10):1203-1211.

2. National Institute for Health and Clinical Excellence. Depression in children and young people. Identification and management in primary, community and secondary care, The British Psychological Society, 2010. URL: http://nice.org.uk/
depression-in-children-and-young-people/CG28 [accessed on February 2011].

3. Geller B, Fox LW, Clank KA. Rate and predictors of prepubertal pibolarity during follow-up of 6- to 12-yearold depressed children. J Am Acad Child Adolesc Psychiat 1994;33(4):461-468.

4. Bridge JA, Iyengar S, Salary CB, Barbe RP, BirmaHER B, Pincus HA et al. Clinical response and risk for reported suicidal ideation and suicide attempts in pediatric antidepressant treatment: a meta-analysis of randomized controlled trials. JAMA 2007;297(15):1683-1696.

5. Tsapakis EM, Soldani F, Tondo L, Baldessarini RJ. Efficacy of antidepressants in juvenile depression: meta-analysis. Br J Psychiatry 2008;193(1):10-17.

6. Masi G, Liboni F, Brovedani P. Pharmacotherapy of major depressive disorder in adolescents. Expert Opin Pharmacother 2010;11(3):375-386.

7. Walkup JT, Albano AM, Piacentini J, Birmaher B, Compton SN, Sherrill JT et al. Cognitive behavioral therapy, sertraline, or a combination in childhood anxiety. New Engl J Med 2008;359(26):2753-2766.

8. Calati R, Pedrini L, Alighieri S, Alvarez Mi, Desideri L, Durante $\mathrm{D}$ et al. Is cognitive behavioural therapy an effective complement to antidepressants in adolescents? A meta-analysis. Acta Neuropsych 2011;23(6):263-271. 